\title{
A Novel Secondary Control for Microgrid Based on Synergetic Control of Multi-Agent System
}

\author{
Zhiwen Yu ${ }^{1, *}$, Qian $\mathrm{Ai}^{1}$, Jinxia Gong ${ }^{2}$ and Longjian Piao ${ }^{1}$ \\ 1 School of Electronic Information and Electrical Engineering, Dongchuan Road, Shanghai Jiaotong University, \\ Shanghai 200240, China; aiqian@sjtu.edu.cn (Q.A.); longjianpiao@gmail.com (L.P.) \\ 2 Department of Electrical Power Engineering, Changyang Road, Shanghai University of Electrical Power, \\ Shanghai 200240 China; gongruth@foxmail.com \\ * Correspondence: yuzhiwen@sjtu.edu.cn; Tel.: +86-21-3420-4584
}

Academic Editor: Josep M. Guerrero

Received: 25 January 2016; Accepted: 21 March 2016; Published: 26 March 2016

\begin{abstract}
In power systems, the secondary control is a very useful way to restore the system frequency and voltage to the rated value. This paper tries to propose a secondary frequency and voltage control of islanded microgrids based on the distributed synergetic control of multi-agent systems. In the proposed control, since each distributed generation only requires its own information and that of the neighbors, the secondary control is fully distributed. The system is more reliable because the central controller and complex communication network are reduced in the distributed structure. Based on multi-agent systems, the dynamic model is established, and distributed synergetic control algorithms are given to design the secondary control of the islanded microgrid. Meanwhile, the system has globally asymptotic stability under the proposed control, which is proved by the direct Lyapunov method. Simulation results about a test microgrid are given to verify the effectiveness of the proposed control.
\end{abstract}

Keywords: microgrid; secondary control; multi-agent system; synergetic control; globally asymptotic stability

\section{Introduction}

Distributed generations (DGs), especially renewable energy sources (RES), are drawing increasing attention from the world due to the lower energy consumption, high efficiency, economy and environmental benefits [1,2]. Microgrids (MG) consisting of a cluster of DGs, loads and storage is a very useful way to consume the small capacity DGs, and plays an increasingly important role in power systems because of the high reliability of power supply [3-8]. However, the operation of MG is very complex, including the grid-connected and islanded modes. Proper controls are necessary to keep operations stable and economically efficient.

In power systems, the frequency and voltage are needed to keep in an expectant range. For this purpose, three levels of control are adopted [9-11]. The primary level is the local automation control to adjust the generated power for dynamic loads. In islanded MG, the droop control is usually used in this level. The secondary layer is centralized or decentralized control which restores the frequency and voltage, and activates in $30 \mathrm{~s}$ to $15 \mathrm{~min}$. Tertiary control considers the economic concerns in the optimal operation of the grid, and dispatches the generators according to the load prediction.

In normal operation, the MG connects to the main grid, and most system dynamics are dictated by the main grid due to the relatively small size of DGs. In the event of disturbances, the MG disconnects from the main grid and switches to the islanded operation, and the system dynamics are dictated by the control of MG. In islanded mode, the primary control is applied to maintain the voltage and frequency stability [5-10]. All DGs are responsible for maintaining the system frequency and voltage 
while sharing the active and reactive power. However, frequency and voltage can still deviate from their nominal values in this case. To restore the frequency and voltage of DGs, the secondary control is necessarily required.

Similarly to the traditional power system, centralized controls [11,12] are introduced to design the secondary control of MG. In centralized controls, a proportion-integral (PI) controller is adopted in MG control central (MGCC) to evaluate the active power deviation between the loads and generators, and then, the MGCC dispatches the active power to each DG according to the droop coefficients. However, a central controller based on a complex communication network, usually with two-way communication links, is required, and then, the system reliability is reduced. Alternatively, synergetic controls based on the distributed communication network are suitable to design the secondary control for more reliable [13]. Compared to centralized control structures, a distributed synergetic control is less impressionable to failures and model errors [12]. Moreover, the operation of plug-and-play about DGs can be applied in this distributed control. In [14-16], a distributed control without communication network based on PI controllers is introduced to traditional droop controls to compensate the active power deviation, and simulation results based on the virtual synchronous generator (VSG) model are given to verify these controls. However, although the communication network is avoided, the system stability is not analyzed, and the voltage deviation is not solved properly. Therefore, the synergetic control based on a spare communication network is proposed to design the secondary control in this paper.

In synergetic control, the structure of multi-agent systems (MAS) has earned much attention because of the flexibility and computational efficiency recently [17-22]. MAS are inspired by the natural phenomena such as swarming in insects, flocking in birds, thermodynamics laws, and synchronization and phase transitions in physical and chemical systems [17]. In MAS, an agent is a kind of complex distributed system with the capacities of self-organization, self-learning and inference $[17,18]$. Agents exchange the information with their neighbors based on certain communication protocols in order to finish difficult tasks by cooperation. In MAS, all agents work for a corporate value that is not prescient at first, and continually close to the one that acts as a leader $[17,18]$.

In power grid, an MG is seen as an MAS, and a DG is considered as an agent [20-22]. In this paper, a novel distributed synergetic control based on MAS is proposed to design the secondary control of MG. Based on the primary control of MG, the issue of secondary control is seen as a tracking synchronization problem that all DGs synchronize to a corporate work state. The secondary-order dynamics model about the system is established. In MG, the expected frequency and voltage are the rated value given at the beginning, which can be seen as a virtual leader in secondary control. Therefore, the synergetic control with a virtual leader is proposed to design the secondary control. Meanwhile, the synergetic control with leaderless is used to control the active power allocation in inverse proportion to the droop coefficients so that the DG with small capacity can work at the mode of plug-and play. In the proposed secondary control, because only a sparse communication network is needed to deliver the active power, frequency and voltage among DGs, and the central controller is avoided, the system is more reliable. At the same time, the MG system with the synergetic control is globally asymptotic stability that is verified by Lyapunov theorem.

The paper is organized as follows: Section 2 discusses the dynamic secondary control model based on the primary control. In Section 3, the secondary frequency and voltage controls based on distributed synergetic control of the secondary-order MAS are presented. In Section 4, the simulations based on a test MG system are given to verify the proposed secondary control. Section 5 discusses the simulation results, and Section 6 concludes the paper.

\section{Dynamic Model of VSC-Based DG Agent}

Most of the DGs, including the photovoltaics, wind turbines and battery energy storage systems, are parallel-connected to MG through voltage source converters (VSCs). The typical structure of VSC is given in Figure 1, which generally is comprised of several parts, such as the power-sharing controller, 
voltage and current controller, inverter and switching process, output filter, coupling inductance and primary source. The model details of each part are described in $[7,23]$, where the DC voltage, which is the input of inverter, is considered fixed. Since the dynamics of the voltage and current controller are much faster than that of the power controller, the combination of inverter, filter, primary sources and energy storages can be considered as a controllable voltage source. In addition, the bandwidth of the inverter voltage controller can be increased using several techniques, as described in [23]. In this paper, we take an inverter as an ideal voltage source with controllable amplitude and frequency [24].

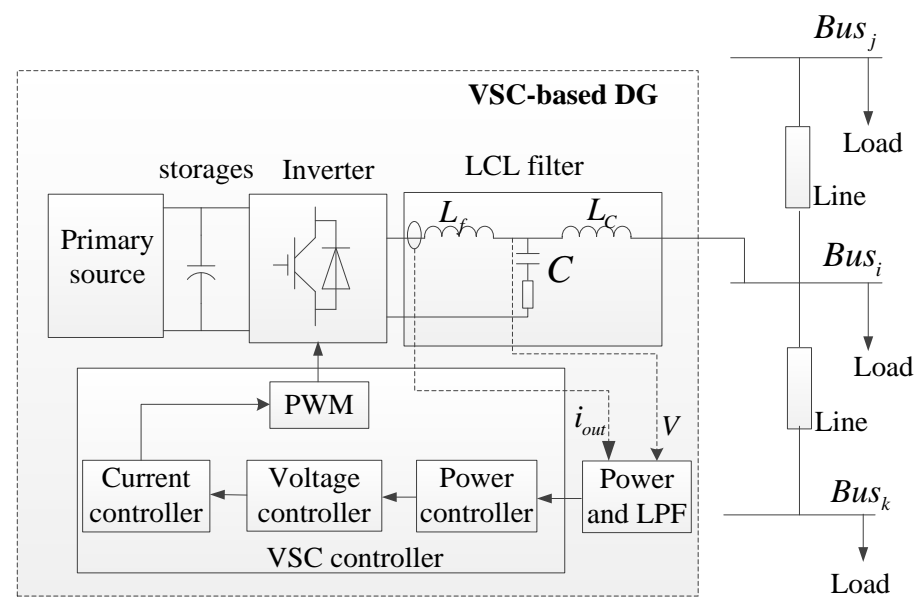

Figure 1. Typical structure of VSC-based DG.

The power flow in MG can be simplified to a two-node system, as shown in Figure 2, which can be written as

$$
\left\{\begin{array}{l}
P=\frac{V_{1}^{2}}{Z} \cos \theta-\frac{V_{1} V_{2}}{Z} \cos \left(\theta+\left(\delta_{1}-\delta_{2}\right)\right) \\
Q=\frac{V_{1}^{2}}{Z} \sin \theta-\frac{V_{1} V_{2}}{Z} \sin \left(\theta+\left(\delta_{1}-\delta_{2}\right)\right),
\end{array}\right.
$$

where $P$ and $Q$ are the active and reactive power from node 1 to node 2 , respectively; and $V_{1}, \delta_{1}$ and $V_{2}, \delta_{2}$ are the voltage and phase of the two nodes, respectively. $Z$ and $\theta$ are the impedance and angle of the transmission line, respectively; $\mathrm{R}$ and $\mathrm{X}$ is the resistance and inductance, respectively.

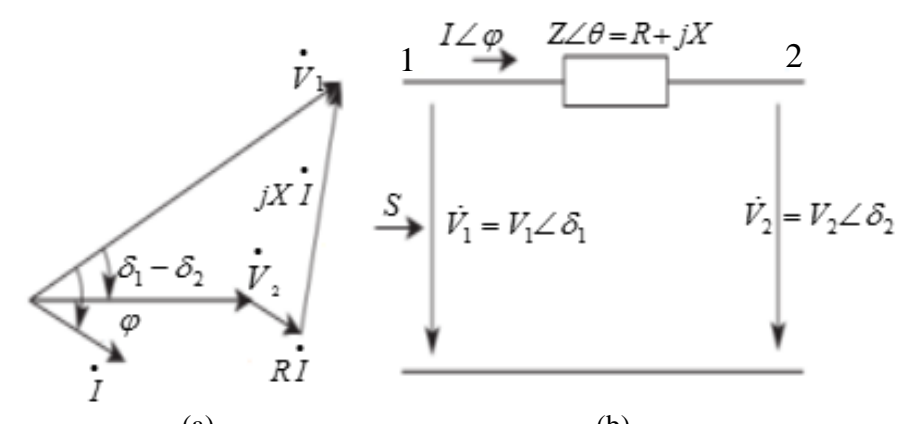

(a)

(b)

Figure 2. Power flow in MGs. (a) voltage vector and (b) power flow.

From Equation (1), by multiplying $Q$ by $R$ and subtracting the product from multiplication of $P$ and $X$, and multiplying $Q$ by $X$ and adding the product from multiplication of $P$ and $R$, we can obtain:

$$
\left\{\begin{array}{l}
X P-R Q=V_{1} * V_{2} \sin \left(\delta_{1}-\delta_{2}\right) \\
R P+X Q=V_{1}^{2}-V_{1} V_{2} \cos \left(\delta_{1}-\delta_{2}\right) .
\end{array}\right.
$$


When neglecting the line resistance (i.e., $R=0$ ), Equation (2) can be rewritten as

$$
\left\{\begin{array}{l}
V_{1} \sin \delta=\frac{X}{V_{2}} P \\
V_{1}-V_{2} \cos \delta=\frac{X}{V_{1}} Q
\end{array}\right.
$$

where $\delta$ is the power angle, i.e., $\delta=\delta_{1}-\delta_{2}$.

Therefore, the active and reactive power of DG can be controlled by drooping the frequency and voltage of the power system, respectively:

$$
\left\{\begin{array}{l}
f=f_{0}-m P \\
V_{d}^{*}=V_{0}-n Q \\
V_{q}^{*}=0,
\end{array}\right.
$$

where $f$ is the output frequency; $V_{d}^{*}$ and $V_{q}^{*}$ are the output voltage in $d$-axis and $q$-axis, respectively; $f_{0}, V_{0}$ are the initial frequency and voltage when the output power is 0 , respectively; $\mathrm{m}$ and $\mathrm{n}$ are the droop parameters, respectively; $P$ and $Q$ are the active and reactive power of DG, respectively.

Equation (4) presents the primary control of islanded MG. High gain angle droop control ensures proper load sharing, especially under weak system conditions. However, it has a negative impact on overall stability such as small signal stability [23]. Furthermore, the voltage and frequency error always exist when operating. The secondary control based on the primary control is needed. In islanded MG, because the droop parameters are usually chosen based on the permitted frequency/voltage errors and DGs' power rating, the purpose of secondary control in islanded MG is to regulate $f_{0}$ and $U_{0}$.

By differentiating the primary control characteristic in Equation (4), we can obtain

$$
\begin{gathered}
\dot{f}=\dot{f}_{0}-m \dot{P} \equiv x_{f}, \\
\dot{V}_{d}=\dot{V}_{0}-m \dot{Q} \equiv x_{v},
\end{gathered}
$$

where $x_{f}$ and $x_{v}$ are the differential value of frequency and voltage, respectively.

Equations (5) and (6) show the first-order dynamic model of secondary control of islanded MG. The first-order system is a time-delay control system, and only the differential of frequency and voltage can be controlled so that the frequency and voltage are close to the target gradually. Then, the auxiliary variables, by expanding Equations (5) and (6), are used to precisely control the differential, that forms the secondary-order model:

$$
\begin{aligned}
& \dot{x}_{f}=u_{c f}, \\
& \dot{x}_{v}=u_{c v},
\end{aligned}
$$

where $u_{c f}$ and $u_{c v}$ are the auxiliary control variables of frequency and voltage, respectively. All DGs' frequency and voltage synchronize to the rated by designing $u_{c f}$ and $u_{c v}$.

Thus, the secondary-order model of MAS-based MG can be written as

$$
\begin{gathered}
\left\{\begin{array}{l}
\dot{f}_{1}=x_{f 1} \\
\dot{x}_{f 1}=u_{c f 1} \\
\cdots
\end{array}\right. \\
\left\{\begin{array}{l}
\dot{f}_{i}=x_{f i} \\
\dot{x}_{f i}=u_{c f i} \\
\ldots
\end{array}\right. \\
\left\{\begin{array}{l}
\dot{f}_{n}=x_{f n} \\
\dot{x}_{f n}=u_{c f n}
\end{array}\right.
\end{gathered}
$$




$$
\begin{gathered}
\left\{\begin{array}{c}
\dot{V}_{d 1}=x_{v 1} \\
\dot{x}_{v 1}=u_{c v 1}
\end{array}\right. \\
\ldots \\
\left\{\begin{array}{l}
\dot{V}_{d i}=x_{v i} \\
\dot{x}_{v i}=u_{c v i} \\
\cdots
\end{array}\right.
\end{gathered},
$$

where the subscript of $i$ and $n$ are the sequence and total number of DGs in islanded MG.

By properly designing the auxiliary variables of $u_{c f i}$ and $u_{c v i}$, the MG can operate at the rated frequency and voltage. However, it should be noted that once the secondary frequency control is applied, the output active power of DG is distributed according to the same method used for primary control [23]. After applying the primary control, the active power satisfies the following equation so that the active power of each DG is proportion to its rated value:

$$
m_{1} P_{1}=m_{2} P_{2}=\cdots=m_{n} P_{n} .
$$

In Equation (11), the droop coefficients $m_{i}$ are set based on the rated active power of DGs $P_{N i}$ [23], which is equivalent to $\frac{P_{1}}{P_{N 1}}=\frac{P_{2}}{P_{N 2}}=\cdots=\frac{P_{n}}{P_{N n}}$, where $P_{N}$ is the rated active power.

The secondary-order model of DG agent can be derived by differentiating Equation (11), and using the same expanding method of secondary frequency and voltage control:

$$
\left\{\begin{array}{l}
m \dot{P}=x_{P} \\
\dot{x}_{P}=u_{c P},
\end{array}\right.
$$

where $u_{c P}$ is the auxiliary control variable of active power control.

Therefore, based on Equation (12), the model of active power allocation of islanded MG can be obtained as follows:

$$
\begin{gathered}
\left\{\begin{array}{c}
m_{1} \dot{P}_{1}=x_{P 1} \\
\dot{x}_{P 1}=u_{c P 1} \\
\cdots
\end{array}\right. \\
\left\{\begin{array}{l}
m_{i} \dot{P}_{i}=x_{P i} \\
\dot{x}_{P i}=u_{c P i} \\
\cdots
\end{array}\right. \\
\left\{\begin{array}{l}
m_{n} \dot{P}_{n}=x_{P n} \\
\dot{x}_{P n}=u_{c P n}
\end{array}\right.
\end{gathered}
$$

Therefore, the active power allocation among DGs can be realized by designing the auxiliary control variable of $u_{c P i}$.

The combination of Equations (9), (10) and (13) forms the secondary-order MAS model of secondary control for islanded MG.

\section{Synergetic Secondary Control of Islanded MG Based on MAS}

The secondary control of islanded MGs is a tracking synchronization problem, where all DGs try to synchronize their terminal voltage amplitude and frequency to the rated values. In MAS-based MG, all agents seek to synchronize to a virtual leader with the rated frequency and voltage (see Figure 3 ). In a distributed synergetic control, each agent needs to exchange the information with its neighboring DGs. In MAS, the spare communication network in MG can be modelled by digraph theorem. 


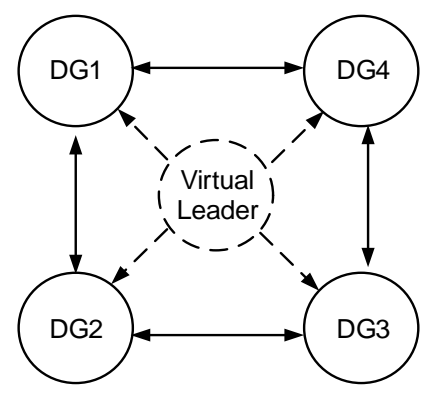

Figure 3. Distributed communication network.

\subsection{Graph Theorem}

The communication network of MG can be modelled by a digraph [25]. In MG, a DG is considered as a node of the communication digraph, and the edges of the communication network symbolize the communication links. A digraph is usually expressed as $G=(V, \varepsilon, A)$ with a non-empty finite set of $\mathrm{N}$ nodes $\mathrm{V}=\left\{v_{1}, v_{2}, \cdots, v_{N}\right\}$, a set of edges or arcs $" \in(\mathrm{V} \times \mathrm{V})$ that is the Cartesian product of $\mathrm{V}$, and the associated adjacency matrix $\mathrm{A}=\left[a_{i j}\right] \in R^{N \times N}$. In this paper, the digraph is assumed to be time-invariant, and then, $\mathrm{A}$ is constant. An edge from node $\mathrm{j}$ to node $\mathrm{i}$ is denoted by $\left(v_{j}, v_{i}\right)$, which means that node $i$ receives the information from node $\mathrm{j}$. In a digraph, $\left(v_{i}, v_{i}\right)$ denotes the edge from node $i$ itself, which is usually neglected. $a_{i j}$ is the weight of edge $\left(v_{j}, v_{i}\right)$, and $a_{i j}>0$ if $\left(v_{j}, v_{i}\right) \in$ ", otherwise $a_{i j}=0$. Node $\mathrm{j}$ is called a neighbor of node $\mathrm{i}$ if $a_{i j}>0$. The set of neighbors of node $i$ is denoted as $N_{i}=\left\{v_{j} \mid\left(v_{j}, v_{i}\right) \in \varepsilon\right\}$. In MG, since all DGs exchange information through communication links, the non-directed graph is considered, that node i can receive/send the information from/to node $\mathrm{j}$ at the same time. The Laplacian matrix of the digraph is defined as $L=\left[l_{i j}\right] \epsilon R^{n \times n}$, where $l_{i j}=-a_{i j}$ if $i \neq j$.

\subsection{Active Power Control}

The active power of DG is allocated according to the droop coefficients used for primary control of islanded MG. Therefore, the active power allocation for secondary control is designed firstly. In this section, the synergetic control is used to design the auxiliary control variables.

To achieve precise power allocation among DGs, it is assumed that DGs communicate with their neighbors through a prescribed communication digraph $G$. Since the active power of DG can not be predicted, the synergetic control with leaderless is adopted in this paper. The auxiliary controls $u_{c P}$ are chosen based on the own information of each DG and the information of its neighbors in Figure 3 as follows:

$$
\begin{gathered}
u_{c P i}=u_{c P \alpha i}+u_{c P \beta i}, \\
u_{c P \alpha i}=-k_{P 1} \sum_{j=1, j \neq i}^{n} a_{i j} \frac{2(m P)_{i j}}{1+(m P)_{i j}^{2}}, \\
u_{c P \beta i}=\sum_{i=1, i \neq j}^{n} a_{i j} \operatorname{sign}\left(x_{P j}-x_{P i}\right)\left|x_{P j}-x_{P i}\right|^{k_{P 2}}, \\
(m P)_{i j}=(m P)_{i}-(m P)_{j},
\end{gathered}
$$

where $u_{c P \alpha i}$ and $u_{c P \beta i}$ are two parts of the auxiliary control $u_{c P i}$, which are given in Equations $(14 \mathrm{a}, \mathrm{b})$, respectively. In the synergetic control, the first part is to directly control the active power of DGs to allocate according to the droop control and the last one is to control the errors of $(m P)$ in each DG 
is to be the same. The non-negative coefficients $k_{P 1}$ and $k_{P 2}$ are two control gains, i.e., $k_{P 1}, k_{P 2} \geqslant 0$. Moreover, sign means the signum function, i.e.,

$$
\operatorname{sign}(x)=\left[\begin{array}{c}
1, \text { when } x \geqslant 0 \\
-1, \text { when } x \leqslant 0
\end{array}\right.
$$

The solutions of Equation (13) $\left(x_{P i}=0\right)$ show that the equilibrium point of the control is $u_{c P i}=0$. Thus, the output active power of DG is allocated in inverse proportion to the droop coefficients. Since the active power allocation is realized, the system stability is also needed to be taken into consideration.

The small signal stability based on the linearization model $[23,24]$ and bifurcation method [26-28] based on nonlinear analysis method are two common-used methods for MG. In this paper, the extended Lyapunov theorem is adopted to analyze the globally asymptotic stability.

In control system, the behavior of a system about its equilibrium point can be studied by Lyapunov's stability theorem [29,30]. Lyapunov's stability theorem allows us to determine the stability for the MG system by analyzing an energy function, which is also called as the Lyapunov function $V(x)$. According to Lyapunov's direct method, the equilibrium point is globally asymptotically stable if $V(x)$ satisfies the following four properties:

(1) $\quad \mathrm{V}(0)=0$;

(2) $\quad \mathrm{V}(\mathrm{x})>0$, for all $\mathrm{x} \neq 0$;

(3) $\mathrm{V}(\mathrm{x}) \rightarrow \infty$ as $\|x\| \rightarrow \infty$;

(4) $\dot{\mathrm{V}}(x)<0$ for all $\mathrm{x} \neq 0$.

To analyze the stability of the active power control in Equation (14), the following Lyapunov function is considered.

$$
V(x)=\frac{1}{2} \sum_{i=1}^{n} x_{P i}^{2}+\frac{1}{2} \sum_{i=1}^{n} \sum_{j=1, j \neq i}^{n} k_{P 1} a_{i j} \operatorname{Ln}\left(1+(m p)_{i j}^{2}\right) .
$$

Obviously, the first three conditions in Lyapunov's theorem are always satisfied. Then, only the last condition is needed to analyze.

By differentiating the Lyapunov function in Equation (17), we obtain the following equation:

$$
\dot{V}(x)=\sum_{i=1}^{n} x_{P i} \dot{x}_{P i}+\frac{1}{2} \sum_{i=1}^{n} \sum_{j=1, j \neq i}^{n} k_{P 1} a_{i j} \frac{2(m P)_{i j}}{1+(m P)_{i j}^{2}}\left((m \dot{P})_{i}-(m \dot{P})_{j}\right) .
$$

Then, add the secondary-order MAS model in Equation (13) to Equation (17)

$\dot{V}(x)=\sum_{i=1}^{n} a_{i j} x_{P i} \sum_{j=1, j \neq i}^{n}\left(-\frac{2 k_{P 1}(m P)_{i j}}{1+(m P)_{i j}^{2}}+\operatorname{sign}\left(x_{P j}-x_{P i}\right)\left|x_{P j}-x_{P i}\right|^{k_{P 2}}\right)+\frac{1}{2} \sum_{i=1}^{n} \sum_{j=1, j \neq i}^{n} k_{P 1} a_{i j} \frac{2(m P)_{i j}}{1+(m P)_{i j}^{2}}\left(x_{P i}-x_{P j}\right)$.

The first and third parts in Equation (18) are always satisfied by the following equation, i.e.,

$$
\sum_{i=1}^{n} x_{P i} \sum_{j=1, j \neq i}^{n} k_{P 1} a_{i j} \frac{2(m P)_{i j}}{1+(m P)_{i j}^{2}}=\frac{1}{2} \sum_{i=1}^{n} \sum_{j=1, j \neq i}^{n} k_{P 1} a_{i j} \frac{2(m P)_{i j}}{1+(m P)_{i j}^{2}}\left(x_{P i}-x_{P j}\right) .
$$

Then, Equation (18) can be simplified to

$$
\dot{V}(x)=\sum_{i=1}^{n} x_{P i} \sum_{j=1, j \neq i}^{n} a_{i j} \operatorname{sign}\left(x_{P j}-x_{P i}\right)\left|x_{P j}-x_{P i}\right|^{k_{P 2}}=\frac{1}{2} \sum_{i=1}^{n} \sum_{j=1, j \neq i}^{n} a_{i j}\left(x_{P i}-x_{P j}\right) \operatorname{sign}\left(x_{P j}-x_{P i}\right)\left|x_{P j}-x_{P i}\right|^{k_{P 2}} .
$$


Consider the signum function in Equation (15), we can obtain the result that the control system in Equation (14) satisfies the following function:

$$
\dot{V}(x) \leqslant 0 .
$$

Thus, all the conditions of Lyapunov's theorem are satisfied, i.e., the stability of synergetic control in Equation (14) leads to globally asymptotic stability.

\subsection{Secondary Voltage Control}

In this section, a distributed synergetic control is designed to control all the voltage magnitudes of DGs $V_{d i}$ to the reference voltage $V_{r e f}$. Because the reference of secondary voltage is given at first, a virtual leader with the rated value is set to design the synergetic control. The auxiliary controls $u_{c v}$ are chosen based on the own information of each DG and the information of its neighbors in Figure 3 as follows:

$$
\begin{gathered}
u_{c v}=u_{c v \alpha i}+u_{c v \beta i}+u_{c v \gamma i}, \\
u_{c v \alpha i}=-k_{v 1} \sum_{j=1, j \neq i}^{n} a_{i j} \frac{2 V_{d i j}}{1+V_{d i j}^{2}}, \\
u_{c v \beta i}=\sum_{i=1, i \neq j}^{n} a_{i j} \operatorname{sign}\left(x_{v j}-x_{v i}\right)\left|x_{v j}-x_{v i}\right|^{k_{v 2},} \\
u_{c v \gamma i}=k_{v 3}\left[-k_{v 1} \frac{2 V_{i L}}{1+V_{i L}^{2}}+\operatorname{sign}\left(x_{v L}-x_{v i}\right)\left|x_{v L}-x_{v i}\right|^{k_{v 2}}\right], \\
V_{d i j}=V_{d i}-V_{d j},
\end{gathered}
$$

where the subscript $L$ means the virtual leader; $u_{c v \alpha i}, u_{c v \beta i}$ and $u_{c v \gamma i}$ are three parts of the auxiliary control $u_{c v i}$ that are given from Equations (22a) to (22c), respectively. In Equation (22), Equation (22a) is to directly control the DG voltage to work to the same value by using its own and the neighbors' voltage; Equation (22b) is to control the voltage errors to be the same, and Equation (22c) is to control the DG to synchronize to the virtual leader. The non-negative coefficients of $k_{v 1}, k_{v 2}$ and $k_{v 3}$ are three control gains, i.e., $k_{v 1}, k_{v 2}, k_{v 3} \geqslant 0$.

Similarly, we use the following Lyapunov function to analyze the system stability:

$$
V(x)=\frac{1}{2} \sum_{i=1}^{n}\left(x_{v i}-x_{v L}\right)^{2}+\frac{1}{2} \sum_{i=1}^{n} \sum_{j=1, j \neq i}^{n} k_{v 1} a_{i j} \operatorname{Ln}\left(1+V_{d i j}^{2}\right)+\sum_{i=1}^{n} k_{v 1} k_{v 3} \operatorname{Ln}\left(1+V_{d i L}^{2}\right) .
$$

According to the analysis results in Equation (16), the above function satisfies the first three conditions in Lyapunov's theorem. By differentiating Equation (23), we obtain

$$
\dot{V}(x)=\sum_{i=1}^{n}\left(x_{v i}-x_{v L}\right) \dot{x}_{v i}+\frac{1}{2} \sum_{i=1}^{n} \sum_{j=1, j \neq i}^{n} k_{v 1} a_{i j} \frac{2 V_{d i j}}{1+V_{d i j}^{2}}\left(\dot{V}_{d i}-\dot{V}_{d j}\right)+\sum_{i=1}^{n} k_{v 1} k_{v 3} \frac{2 V_{d i L}}{1+V_{d i L}^{2}}\left(\dot{V}_{d i}-\dot{V}_{d L}\right) .
$$

Then, adding the secondary-order MAS model in Equation (10) to Equation (24), and utilizing the analysis results in Equation (19), we can obtain

$$
\dot{V}(x)=\sum_{i=1}^{n}\left(x_{v i}-x_{v L}\right)\left(u_{c v a i}+u_{c v \beta i}+u_{c v \gamma i}\right)+\sum_{i=1}^{n} k_{v 1} k_{v 3} \frac{2 V_{d i L}}{1+V_{d i L}^{2}}\left(V_{d i}-V_{d L}\right)+\frac{1}{2} \sum_{i=1}^{n} \sum_{j=1, j \neq i}^{n} k_{v 1} a_{i j} \frac{2 V_{d i j}}{1+V_{d i j}^{2}}\left(\dot{V}_{d i}-\dot{V}_{d j}\right) .
$$

Suppose that $\hat{x}_{v i}=x_{v i}-x_{v L}$. Then, we can obtain

$$
x_{v i}-x_{v j}=\hat{x}_{v i}-\hat{x}_{v j}
$$


Adding Equations (19) and (26) to Equation (25) yields:

$$
\dot{V}(x)=\sum_{i=1}^{n} \widehat{x}_{v i} \sum_{j=1, j \neq i}^{n} a_{i j} \operatorname{sign}\left(\widehat{x}_{v j}-\widehat{x}_{v i}\right)\left|\widehat{x}_{v j}-\widehat{x}_{v i}\right|^{k_{v 2}}+k_{v 3} \sum_{i=1}^{n} \widehat{x}_{v i} \operatorname{sign}\left(-\widehat{x}_{v i}\right)\left|-\widehat{x}_{v i}\right|^{k_{v 2}} \text {. }
$$

According to the analysis results in Equation (20), the secondary voltage control always satisfies the conditions in Lyapunov's theorem. Therefore, the synergetic secondary voltage control has globally asymptotic stability.

The block diagram of the secondary voltage control based on the distributed synergetic control is shown in Figure 4. The control input $V_{o i}$ is

$$
V_{o i}=\int\left(n_{i} \dot{Q}_{i}+\int u_{c v i} d t\right) d t+V_{o i 0}
$$

where $V_{o i 0}$ is the initial value of $V_{o i}$ in the primary control, and $Q_{i}$ is the reactive power in the primary control [23].

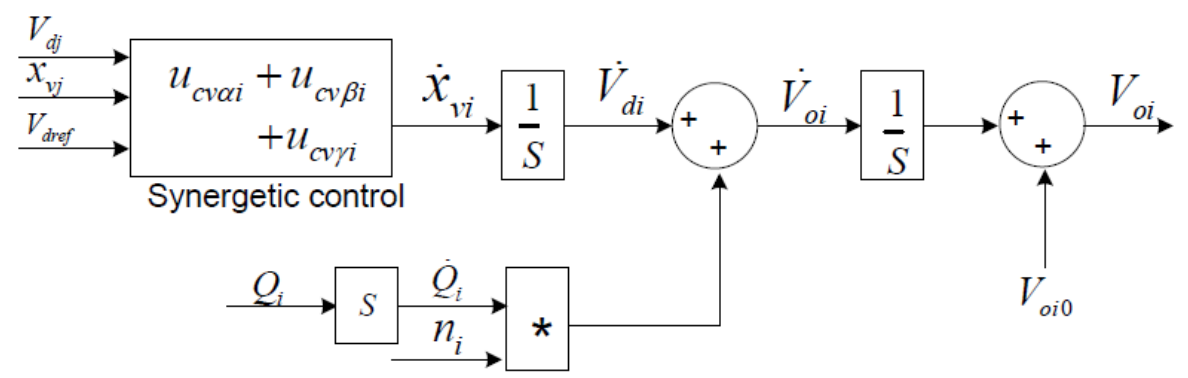

Figure 4. Diagram of the synergetic secondary voltage control.

\subsection{Secondary Frequency Control}

In this section, a distributed synergetic control is designed to control the frequency in each DG to the reference value of $f_{N}$. To complete the target, it is assumed that DGs can communicate with each other through a prescribed communication digraph $G$. The auxiliary variable $u_{c f i}$ is chosen based on its own information and its neighbors in Figure 3 as follows:

$$
\begin{gathered}
u_{c f i}=u_{c f \alpha i}+u_{c f \beta i}+u_{c f \gamma i}, \\
u_{c f \alpha i}=-k_{f 1} \sum_{j=1, j \neq i}^{n} a_{i j} \frac{2 f_{i j}}{1+f_{i j}^{2}}, \\
u_{c f \beta i}=\sum_{i=1, i \neq j}^{n} a_{i j} \operatorname{sign}\left(x_{f j}-x_{f i}\right)\left|x_{f j}-x_{f i}\right|^{k_{f 2}}, \\
u_{c f \gamma i}=k_{f 3}\left[-k_{f 1} \frac{2 f_{i L}}{1+f_{i L}^{2}}+\operatorname{sign}\left(x_{f L}-x_{f i}\right)\left|x_{f L}-x_{f i}\right|^{k_{f 2}}\right], \\
f_{i j}=f_{i}-f_{j},
\end{gathered}
$$

where $u_{c f \alpha i}, u_{c f \beta i}$ and $u_{c f \gamma i}$ are three parts of the auxiliary control $u_{c f i}$ that are given from Equation (29a) to (29c), respectively. In Equation (29), Equation (29a) is to directly control the frequency to work to the same value by using its own and the neighbors' information; Equation (29b) is to control the frequency error to be the same, and Equation (29c) is to control the DG to synchronize with the virtual leader. The non-negative coefficients $k_{f 1}, k_{f 2}$ and $k_{f 3}$ are three control gains, i.e. $k_{f 1}, k_{f 2}, k_{f 3} \geqslant 0$. 
According to the analysis results in the secondary voltage control, we can obtain that the secondary frequency control in Equation (29) also has globally asymptotic stability. Therefore, the secondary frequency control input $f_{o i}$ is

$$
f_{o i}=\int\left(m_{i} \dot{P}_{i}+\int u_{c f i} d t\right) d t+f_{o i 0}
$$

where $f_{o i 0}$ is the initial value of $f_{o i}$ in the primary control.

Because the active power of DGs needs to be allocated according to Equation (11), the active power $P_{i}$ in secondary frequency control is obtained from Equation (14), but not the value calculated from the DG's output current and voltage. Then, the whole secondary frequency is

$$
f_{o i}=\int\left(\int u_{c P i} d t+\int u_{c f i} d t\right) d t+f_{o i 0} .
$$

Based on the distributed synergetic control, the block diagram of the secondary frequency control is illustrated in Figure 5.

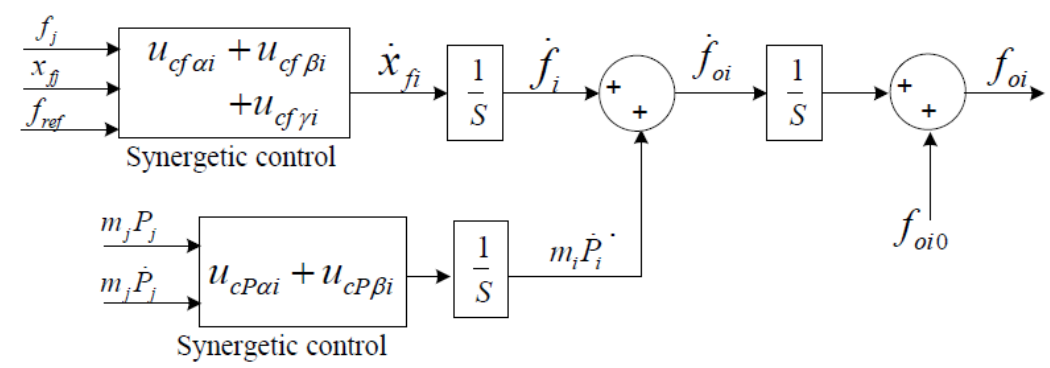

Figure 5. Diagram of synergetic secondary frequency control.

\section{Simulation}

An islanded MG illustrated in Figure 6 is used to verify the effectiveness of the synergetic secondary control [22], which consists of four DGs. The DG is considered as a controllable voltage source. The rated power of DG1 and DG2 is $100 \mathrm{kVA}$, and that of DG3 and DG4 is $75 \mathrm{kVA}$. The lines are modelled as series RL branches. The parameters of the DGs, lines, and loads are given in Table 1. The dynamic simulation is done in EMTP, and the results are analyzed with Matlab.

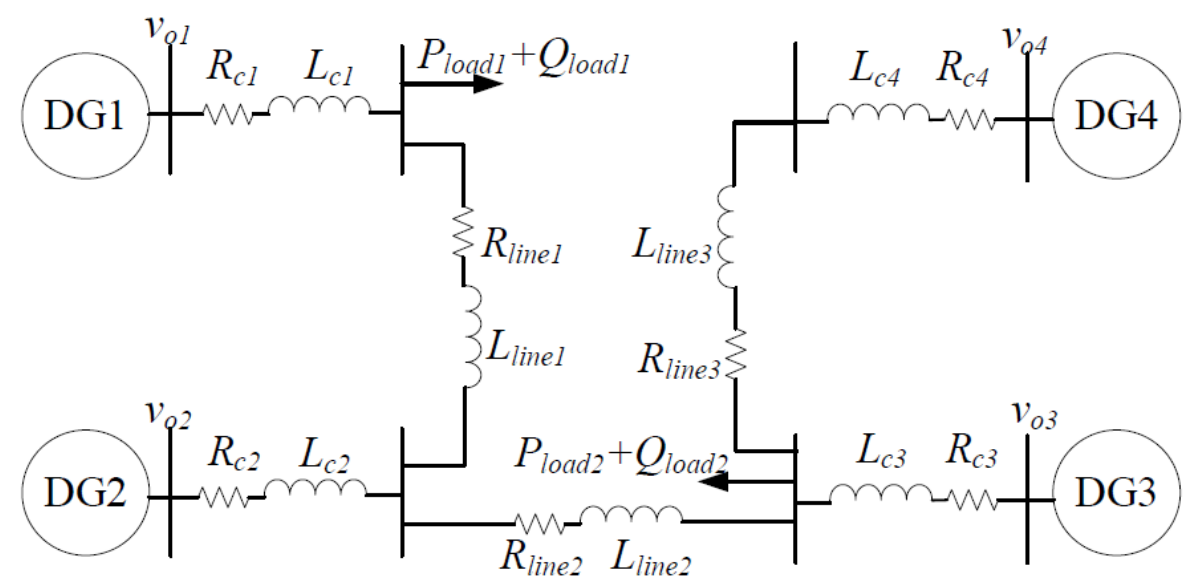

Figure 6. Test islanded MG. 
Table 1. Parameters of the MG system.

\begin{tabular}{|c|c|c|c|c|}
\hline DGs & $R_{c 1}=R_{c}$ & $=R_{c 4}$ & & $=L_{c 4}$ \\
\hline \multirow[b]{2}{*}{ Lines } & \multicolumn{2}{|c|}{ Line 1} & \multicolumn{2}{|c|}{ Line 2} \\
\hline & $\begin{array}{c}R_{\text {Line1 } 1}=R_{\text {Line3 }} \\
0.23 \Omega\end{array}$ & $\begin{array}{c}L_{\text {Line1 } 1}=L_{\text {Line } 3} \\
0.318 \mathrm{mH}\end{array}$ & $\begin{array}{l}R_{\text {Line2 }} \\
0.35 \Omega\end{array}$ & $\begin{array}{c}L_{\text {Line2 }} \\
1.847 \mathrm{mH}\end{array}$ \\
\hline \multirow{2}{*}{ Loads } & \multicolumn{2}{|c|}{ Load 1} & \multicolumn{2}{|c|}{ Load 2} \\
\hline & $\begin{array}{c}\mathrm{P}_{1}(\mathrm{~kW}) \\
36\end{array}$ & $\begin{array}{c}\mathrm{Q}_{1}(\mathrm{kVar}) \\
36\end{array}$ & $\begin{array}{c}\mathrm{P}_{2}(\mathrm{~kW}) \\
45.9\end{array}$ & $\begin{array}{c}\mathrm{Q}_{2}(\mathrm{kVar}) \\
22.8\end{array}$ \\
\hline
\end{tabular}

It is assumed that the DGs communicate with each other as depicted in Figure 3. The Laplace matrix of the digraph is

$$
\mathrm{L}=\left[\begin{array}{crcr}
0 & -1 & 0 & -1 \\
-1 & 0 & -1 & 0 \\
0 & -1 & 0 & -1 \\
-1 & 0 & -1 & 0
\end{array}\right]
$$

The reference value for the MG frequency and terminal amplitude voltage of DGs are $f_{\text {ref }}=50 \mathrm{~Hz}$ and $V_{\text {diref }}=311 \mathrm{~V}$. The control gains for secondary control are given in Table 2. It is assumed that the islanded MG starts to work with the primary control, and the secondary control works at $t=1.2 \mathrm{~s}$. The secondary frequency and voltage control results are shown in Figures 7 and 8 respectively.

Table 2. Parameters of the primary and secondary control.

\begin{tabular}{ccccc}
\hline \multirow{2}{*}{ Primary control } & $\mathbf{m}_{\mathbf{p 1}}=\mathbf{m}_{\mathbf{p} 2}$ & $\mathbf{n}_{\mathbf{Q} 1}=\mathbf{n}_{\mathbf{Q} 2}$ & $\mathbf{m}_{\mathbf{p} 3}=\mathbf{m}_{\mathbf{p} 4}$ & $\mathbf{n}_{\mathbf{Q} 3}=\mathbf{n}_{\mathbf{Q} 4}$ \\
& 0.000094 & 0.0013 & 0.000125 & 0.0015 \\
\hline \multirow{3}{*}{ Fecondary } & \multirow{2}{*}{ Frequency } & $\mathrm{k}_{f 1}$ & $\mathrm{k}_{f 2}$ & $\mathrm{k}_{f 3}$ \\
\cline { 2 - 5 } control & \multirow{2}{*}{ Voltage } & $\mathrm{k}_{v 1}$ & 0.8 & 800 \\
\cline { 2 - 5 } & & 150 & $\mathrm{k}_{v 2}$ & $\mathrm{k}_{v 3}$ \\
& \multirow{2}{*}{ Active power } & $\mathrm{k}_{P 1}$ & 0.8 & 3 \\
\hline
\end{tabular}

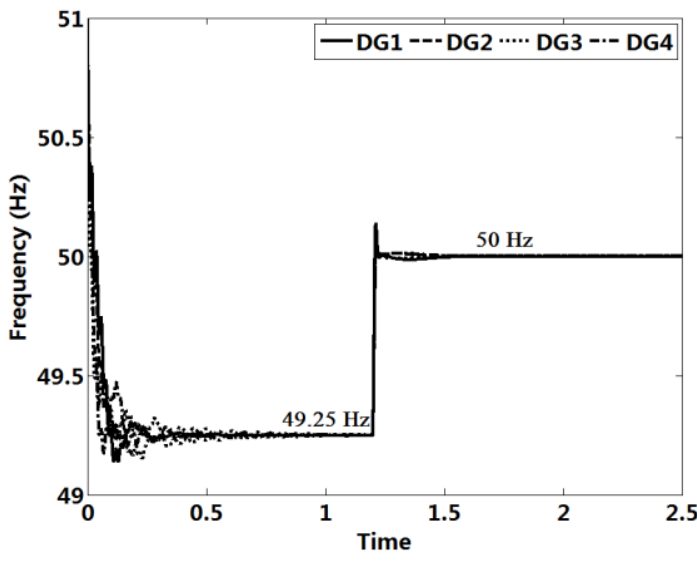

(a)

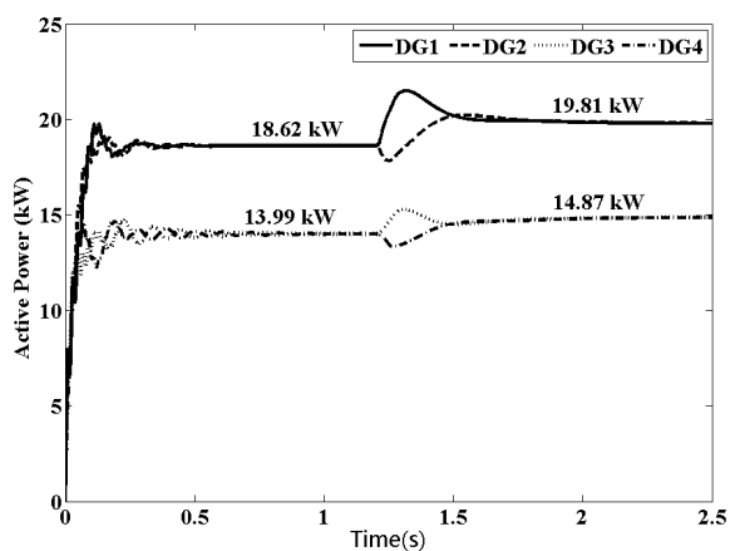

(b)

Figure 7. Simulation results of the secondary frequency control. (a) the islanded MG frequency and (b) the active power of DGs. 


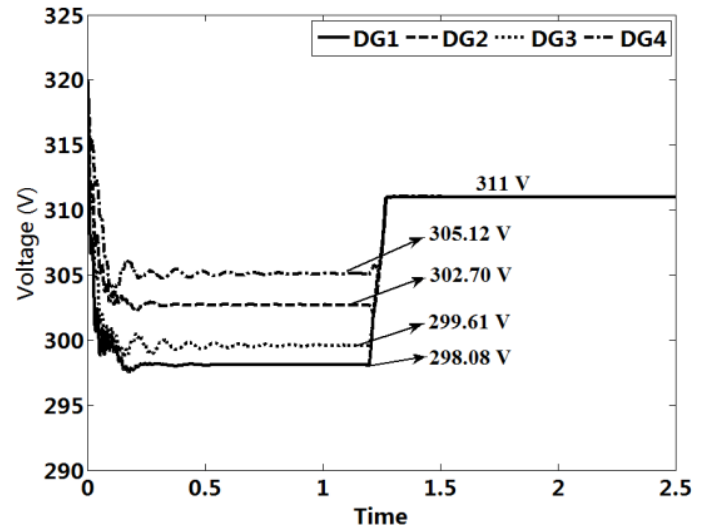

(a)

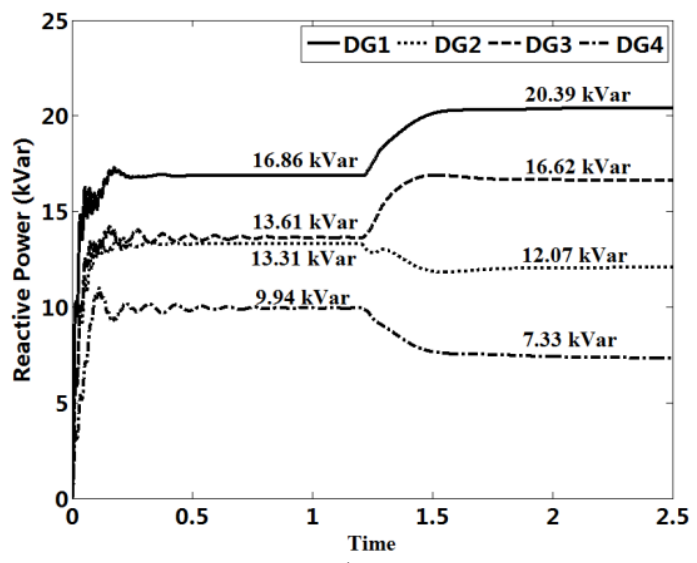

(b)

Figure 8. Simulation results of the secondary voltage control. (a) the amplitude voltage and (b) the reactive power of DGs.

\section{Discussion}

As seen in Figure 7, the islanded MG starts to work with primary control and goes to stability state after $0.8 \mathrm{~s}$. In Figure $7 \mathrm{a}$, the operating frequencies all go to a common value $(49.3 \mathrm{~Hz})$ less than the rated, which is the frequency of MG. Due to the primary control, the output active power of the four DGs is allocated according to their droop parameters. After $1.2 \mathrm{~s}$, the secondary frequency control in Equation (31) is applied, and the operating frequency of the islanded MG returns to its rated value after about $0.3 \mathrm{~s}$, shown in Figure $7 \mathrm{a}$. As seen in Figure $7 \mathrm{~b}$, the output active power of DGs is allocated in inverse proportion to the droop parameters because the distributed active power control in Equation (14) is applied.

Figure 8 presents the voltage and reactive power of DGs. Similar to the frequency control, the terminal voltages of DGs works with a different value less than the rated $V_{r e f}$. Once the synergetic secondary control is applied, all the DGs' voltage $V_{\text {odi }}$ returns to the rated value, as shown in Figure 8a. Because of the application of primary in Equation (4), the quadratic term of DG voltage is 0. Therefore, the active and reactive power of DGs is re-allocated according to the primary control, which corresponds to the results shown in Figures $7 \mathrm{~b}$ and $8 \mathrm{~b}$, respectively.

In power systems, since the system frequency error can be used to measure the active power deviation, the centralized control based on the secondary control in traditional power grid can be used to restore the system frequency, which has been verified in [9-11]. However, the system with centralized control may be unstable based on the analysis results in [23], which is globally asymptotic stability under the proposed control. Meanwhile, the secondary voltage control is very complex through the centralized control for the following reasons. Firstly, the reactive power deviation of the grid cannot be derived directly through the same way because the voltage at each node is not the same. In addition, even though the reactive power deviation is obtained, its allocation is still a complex problem because the power flow is different to the traditional power grid while the balance point of the grid does not exist in droop-controlled MG.

\section{Conclusions}

In this paper, the distributed synergetic control based on MAS is proposed to design the secondary control of MG. In MAS, DGs communicate with their nearest neighbors through a communication network modelled by digraph theorem. Based on primary controls, the secondary-order differential-algebraic equations are used to describe the dynamics of agents. The synergetic control is used to design the distributed secondary frequency and voltage control. In the proposed control, the auxiliary variables are designed so that each DG only requires its own and its 
neighbors' information in the communication network. The Lyapunov theorem is used to verify the globally asymptotic stability. In the proposed secondary control, since the complex communication network is avoided, the system is more reliable. The distributed control structure provides a robust secondary control framework, which is able to appropriately operate in time varying and unreliable communication networks.

Acknowledgments: This work was supported by the National Natural Science Foundation of China (No. 51577115).

Author Contributions: All the authors contributed to this work. Zhiwen Yu designed the study, performed the analysis, performed simulations, and wrote the first draft of the paper. Qian Ai set the simulation environment, and checked the overall logic of this work. Jinxia Gong and Longiian Piao contributed to providing important comments on the modeling and thoroughly revised the paper.

Conflicts of Interest: The authors declare no conflict of interest.

\section{References}

1. Diaz, G.; Gonzalez-Moran, C.; Gomez-Aleixandre, J.; Diez, A. Complex-valued state matrices for simple representation of large autonomous microgrids supplied by PQ and VF generation. IEEE Trans. Power Syst. 2009, 24, 1720-1730.

2. Li, Y.; Vilathgamuwa, D.M.; Loh, P.C. Design, analysis and realtime testing of a controller for multibus microgrid system. IEEE Trans. Power Electron. 2004, 19, 1195-1204. [CrossRef]

3. Huang, A.Q.; Crow, M.L.; Heydt, G.T.; Zheng, J.P.; Dale, S.J. The future renewable electric energy delivery and Management (FREEDM) system: the energy internet. IEEE Proc. 2011, 99, 133-148. [CrossRef]

4. Majumder, R.; Ledwich, G.; Ghosh, A.; Chakrabarti, S.; Zare, F. Droop control of converter-interfaced microsources in rural distributed generation. IEEE Trans. Power Deliv. 2010, 25, 2768-2778. [CrossRef]

5. Lopes, J.A.P.; Moreira, C.L.; Madureira, A.G. Defining control strategies for microgrids islanded operation. IEEE Trans. Power Syst. 2006, 21, 916-924. [CrossRef]

6. Pourmousavi, S.A.; Nehrir, M.H.; Colson, C.M.; Wang, C. Real-time energy management of a stand-alone hybrid wind-microturbine energy system using particle swarm optimization. IEEE Trans. Sustain. Energy 2010, 1, 193-201. [CrossRef]

7. Barklund, E.; Pogaku, N.; Prodanovic, M.; Hernandez-Aramburo, C.; Green, T.C. Energy management in autonomous microgrid using stability-constrained droop control of inverters. IEEE Trans. Power Electron. 2008, 23, 2346-2352. [CrossRef]

8. Divshali, P.H.; Hosseinian, S.H.; Abedi, M. A novel multi-stage fuel cost minimization in a VSC-based microgrid considering stability, frequency and voltage constraint. IEEE Trans. Power Syst. 2013, 28, 931-939. [CrossRef]

9. Wen, T.A.N. Load frequency control: Problems and solutions. In Proceedings of the 2011 30th Chinese Control Conference (CCC), Yantai, China, 22-24 July 2011; pp. 6281-6286.

10. Sun, Y.; Zhang, Z.; Li, G.; Lin, J. Review on frequency control of power systems with wind power penetration. In Proceedings of the 2010 International Conference on Power System Technology (POWERCON), Hangzhou, China, 24-28 October 2010; pp. 1-8.

11. Bidram, A.; Davoudi, A. Hierarchical structure of microgrids control system. IEEE Trans. Smart Grid 2012, 3, 1963-1976. [CrossRef]

12. Hui, Q.; Haddad, W. Distributed nonlinear control algorithms for network consensus. Automatica 2008, 42, 2375-2381. [CrossRef]

13. Savaghebi, M.; Jalilian, A.; Vasquez, J.; Guerrero, J. Secondary control scheme for voltage unbalance compensation in an islanded droop-controlled microgrid. IEEE Trans. Smart Grid 2010, 3, 797-807. [CrossRef]

14. Zhao, H.; Zhu, G.; Xu, C. A novel frequency control strategy of micro-source based on the secondary frequency regulation of power system. In Proceedings of the 2012 China International Conference on Electricity Distribution (CICED), Shanghai, China, 10-14 September 2012; pp. 1-6.

15. Santi, E.; Monti, A.; Li, D.; Proddutur, K.; Dougal, R.A. Synergetic control for DC-DC boost converter: Implementation options. IEEE Trans. Ind. Appl. 2003, 39, 1803-1813. [CrossRef]

16. Jiang, Z.; Dougal, R.A. Synergetic control of power converters for pulse current charging of advanced batteries from a fuel cell power source. IEEE Trans. Power Electron. 2004, 19, 1140-1150. [CrossRef] 
17. Jadbabaie, A.; Lin, J.; Morse, A.S. Coordination of groups of mobile autonomous agents using nearest neighbor rules. IEEE Trans. Autom.Control 2003, 48, 988-1001. [CrossRef]

18. Li, Z.; Duan, Z.; Chen, G.; Huang, L. Consensus of multi-agent systems and synchronization of complex networks: a unified viewpoint. IEEE Trans. Circuits Syst. I 2010, 57, 213-224.

19. Majumder, R.; Chaudhuri, B.; Ghosh, A.; Majumder, R.; Ledwich, G.; Zare, F. Improvement of stability and load sharing in an autonomous microgrid using supplementary droop control droop. IEEE Trans. Power Syst. 2010, 25, 796-808. [CrossRef]

20. Bidram, A.; Davoud, A.; Lewis, F.L.; Qu, Z. Secondary control of microgrids based on distributed cooperative control of multi-agent system. IET Gener.Transm. Distrib. 2013, 7, 822-831. [CrossRef]

21. Liu, W.; Gu, W.; Sheng, W.; Meng, X.; Wu, Z.; Chen, W. Decentralized multi-agent system-based cooperative frequency control for autonomous microgrids with communication constraints. IEEE Trans. Sustain. Energy 2014, 5, 446-456. [CrossRef]

22. Bidram, A.; Davoudi, A.; Lewis, F.L.; Guerrero, J.M. Distributed Cooperative Secondary Control of Microgrids Using Feedback Linearization. IEEE Trans. Power Syst. 2013, 28, 3462-3470. [CrossRef]

23. Pogaku, N.; Prodanovic, M.; Green, T.C. Modeling, analysis and testing of autonomous operation of an inverter-based microgrid. IEEE Trans. Power Electron. 2007, 22, 613-625. [CrossRef]

24. Coelho, E.A.A.; Cortizo, P.; Gracia, P.F.D. Small signal stability for parallel-connected inverters in stand-alone ac supply systems. IEEE Trans. Ind. Appl. 2002, 38, 533-542. [CrossRef]

25. Fax, J.; Murray, R. Information flow and cooperative control of vehicle formations. IEEE Trans. Autom. Control 2004, 49, 1465-1476. [CrossRef]

26. Divshali, P.H.; Hosseinian, S.H.; Azadani, E.N.; Abedi, M. Application of bifurcation theory in dynamic security constrained optimal dispatch in deregulated power system. Elect. Eng. 2011, 93, 157-166. [CrossRef]

27. Wen, X.; Ajjarapu, V. Application of a novel eigenvalue trajectory tracing method to identify both oscillatory stability margin and damping margin. IEEE Trans. Power Syst. 2006, 21, 817-824. [CrossRef]

28. Vahidi, B.; Azadani, E.N.; Divshali, P.H.; Hessaminia, A.H.; Hosseinian, S.H. Novel approach for determination of worst loading direction and fast prediction of stability margin in power systems. Simulation 2009, 86, 729-741. [CrossRef]

29. Rahmani, S.; Hamadi, A.; Al-Haddad, K. A Lyapunov-function-based control for a three-phase shunt hybrid active filter. IEEE Trans. Ind. Electron. 2012, 59, 1418-1429. [CrossRef]

30. Komurcugil, H.; Altin, N.; Ozdemir, S.; Sefa, I. An extended lyapunov-function-based control strategy for single-phase UPS inverters. IEEE Trans. Power Electron. 2015, 30, 3976-3983. [CrossRef]

(C) 2016 by the authors; licensee MDPI, Basel, Switzerland. This article is an open access article distributed under the terms and conditions of the Creative Commons by Attribution (CC-BY) license (http:/ / creativecommons.org/licenses/by/4.0/). 